\title{
How Does Labrador Sea Water Enter the Deep Western Boundary Current?
}

\author{
Jaime B. PALTER AND M. Susan LOZIER \\ Division of Earth and Ocean Science, Nicholas School of the Environment and Earth Science, Duke University, \\ Durham, North Carolina \\ KARA L. LAVENDER \\ Woods Hole Oceanographic Institution, Woods Hole, Massachusetts
}

(Manuscript received 20 March 2007, in final form 10 September 2007)

\begin{abstract}
Labrador Sea Water (LSW), a dense water mass formed by convection in the subpolar North Atlantic, is an important constituent of the meridional overturning circulation. Understanding how the water mass enters the deep western boundary current (DWBC), one of the primary pathways by which it exits the subpolar gyre, can shed light on the continuity between climate conditions in the formation region and their downstream signal. Using the trajectories of (profiling) autonomous Lagrangian circulation explorer [(P)ALACE] floats, operating between 1996 and 2002, three processes are evaluated for their role in the entry of Labrador Sea Water in the DWBC: 1) LSW is formed directly in the DWBC, 2) eddies flux LSW laterally from the interior Labrador Sea to the DWBC, and 3) a horizontally divergent mean flow advects LSW from the interior to the DWBC. A comparison of the heat flux associated with each of these three mechanisms suggests that all three contribute to the transformation of the boundary current as it transits the Labrador Sea. The formation of LSW directly in the DWBC and the eddy heat flux between the interior Labrador Sea and the DWBC may play leading roles in setting the interannual variability of the exported water mass.
\end{abstract}

\section{Introduction and background}

The Labrador Sea is a region where intense air-sea heat exchange creates deep, dense ocean mixed layers that are ultimately exported from their formation region to ventilate the intermediate depths of the North Atlantic and beyond. The final product of such convective mixing, the Labrador Sea Water (LSW) is a constituent of the meridional overturning circulation (MOC). Because of its climatic importance, LSW has been the subject of various studies that have revealed considerable spatial and temporal variability associated with the formation and meridional transport of this water mass (Dickson et al. 1996; Kieke et al. 2006; Rhein et al. 2002; Stramma et al. 2004).

Though a connection between convective variability within the Labrador Sea and its downstream signal is

Corresponding author address: Jaime Palter, Centro Mediterraneo de Investigaciones Marinas y Ambientales (CSIC), Passeig Maritimo de la Barceloneta, 37-49, 08003 Barcelona, Spain.

E-mail: palter@icm.csic.es generally accepted, the spatial and temporal dimensions of this connection require an understanding of the formation of the water mass and its export pathways. Temporal variability in LSW properties and transport has been observed at several scales both within the Labrador Sea and far afield. Stramma et al. (2004) recently plotted LSW properties over the past 60 years, using hydrographic data taken within the Labrador Sea (reproduced here as Fig. 1). In this time series, interannual and interdecadal variability is apparent, with temperature variations in the LSW core of nearly $1^{\circ} \mathrm{C}$. Directly downstream of this region, over $1000 \mathrm{~km}$ to the south of the Labrador Sea, interannual temperature variations of roughly $0.5^{\circ} \mathrm{C}$ at the approximate LSW depth have been recorded by an array of moorings over the past several years (Schott et al. 2006). Finally, temperature changes of nearly $0.3^{\circ} \mathrm{C}$ at middepths in the subtropics, several thousands of kilometers from the Labrador Sea, are thought to be linked to upstream changes in LSW (Curry et al. 1998). However, it is not clear how the upstream changes in LSW translate to downstream variability. 

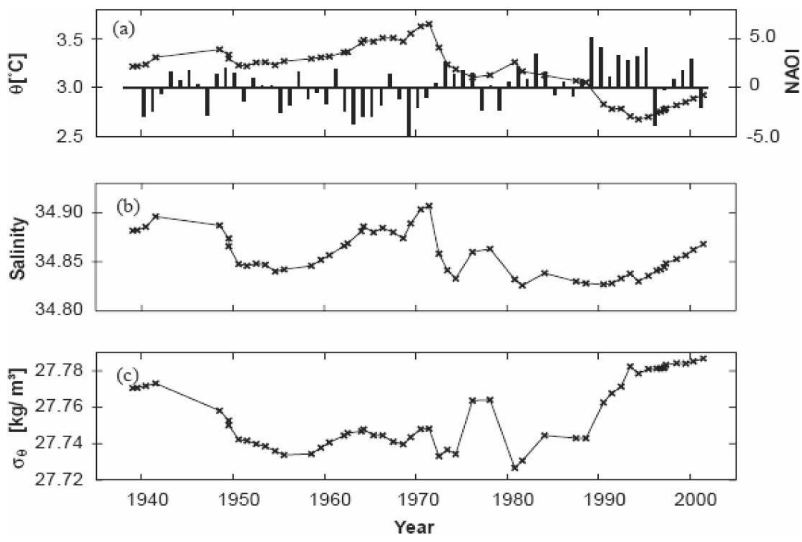

FIG. 1. (a) Potential temperature, (b) salinity, and (c) potential density in the core of the LSW from the AR7W hydrographic line. The core of the LSW was identified as the thickest density class from the hydrographic stations in water deeper than $3300 \mathrm{~m}$. The vertical bars in (a) are the North Atlantic Oscillation (NAO) index. Reproduced from Stramma et al. (2004).

From myriad hydrographic and tracer studies, the deep western boundary current (DWBC) is understood to be a major export pathway for recently ventilated LSW (Pickart and Smethie 1998; Rhein et al. 2002; Talley and McCartney 1982). Therefore, it is our objective to investigate the mechanisms that regulate the entry of LSW into the DWBC. We pose three potential mechanisms, as schematized in Fig. 2: 1) LSW is formed directly in the DWBC, 2) eddies flux LSW laterally from the interior Labrador Sea to the DWBC, and 3) a horizontally divergent mean flow advects LSW from the interior to the DWBC. Understanding how these mechanisms influence the entry of LSW into the boundary current can shed light on the water mass's residence time in the Labrador Sea and the continuity between climate variability in the formation region and its downstream signal. Our objective is to assess how each of these mechanisms contributes to setting the properties and temporal variability of the exported LSW. We build on these previous studies by studying all three processes with data collected contemporaneously using (profiling) autonomous Lagrangian circulation explorer [(P)ALACE] floats between 1996 and 2002 (Davis et al. 2001), comparing the degree to which each mechanism caused heat loss from the DWBC during the float years, and how these processes may contribute to interannual variability of the exported LSW.

\section{Data and methods}

The data used in this study come from 211 isobaric, subsurface (P)ALACE floats deployed as part of the World Ocean Circulation Experiment (WOCE) and the Labrador Sea Deep Convection Experiment (The

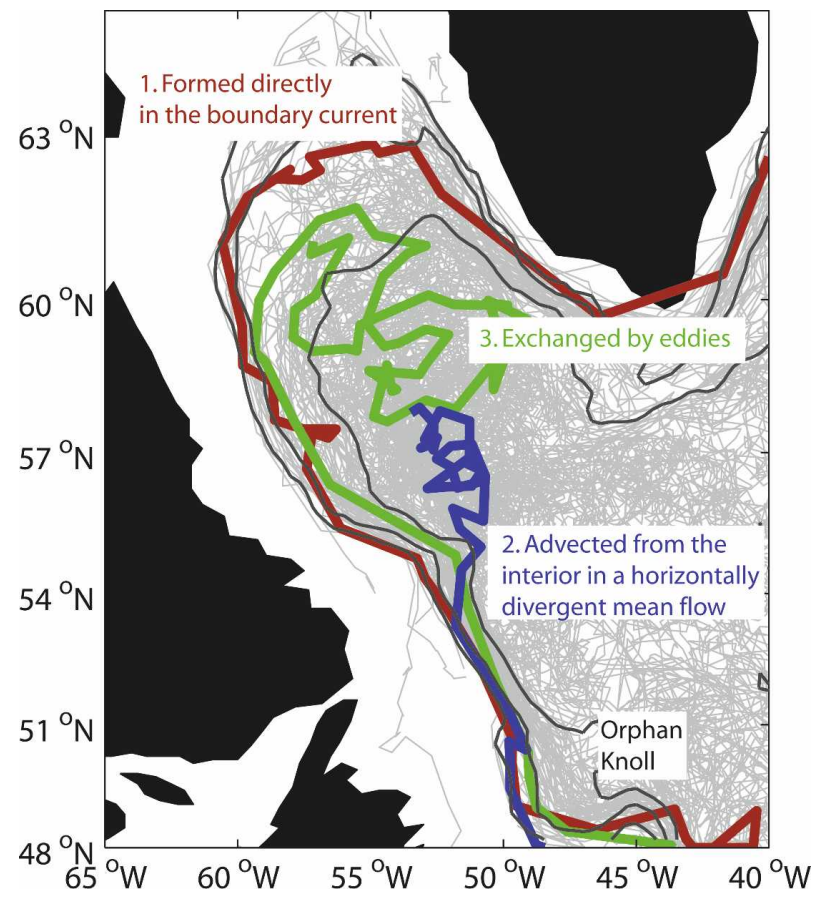

FIG. 2. The study site, with the trajectories of all floats used in this study (gray tracks). The 1000-, 2000-, and 3000-m isobaths smoothed by a $1 / 3^{\circ}$ filter are shown in black. The red, green, and blue trajectories are highlighted to schematize the three potential mechanisms responsible for the presence of LSW in the DWBC.

Lab Sea Group 1998). For a detailed description of the floats, their launch locations, and spatial coverage, see Lavender et al. (2005). Briefly, the floats, designed to drift at approximate pressures of 400,700 , or $1500 \mathrm{db}$, were deployed throughout the North Atlantic subpolar gyre, with a high number deployed in the western Labrador Sea as part of the Deep Convection Experiment (The Lab Sea Group 1998). Each float drifts at its target depth for 3.5 to 20 days, then ascends to the surface in approximately $4 \mathrm{~h}$ where it drifts for 12 to $24 \mathrm{~h}$ while communicating with the Argos satellite system. The floats collect temperature and conductivity profiles either during their ascent or descent. The trajectories of the floats are quasi-Lagrangian, as the ascent, descent, and surface drift can distort the trajectory of the float relative to that of the fluid parcel it initially tags. To study the export properties of LSW, we use those float profiles and displacements in the region between Greenland and Canada and north of a southern boundary drawn diagonally from the tip of Greenland to Newfoundland, just south of the WOCE AR7W repeat hydrographic line. A map of all 5122 profile locations within that region, and in the surrounding boundary current region, is shown in Fig. 3 with a smoothed 2500-m isobath. These profiles are grouped according to their dynamic region: the interior Labrador Sea, the 


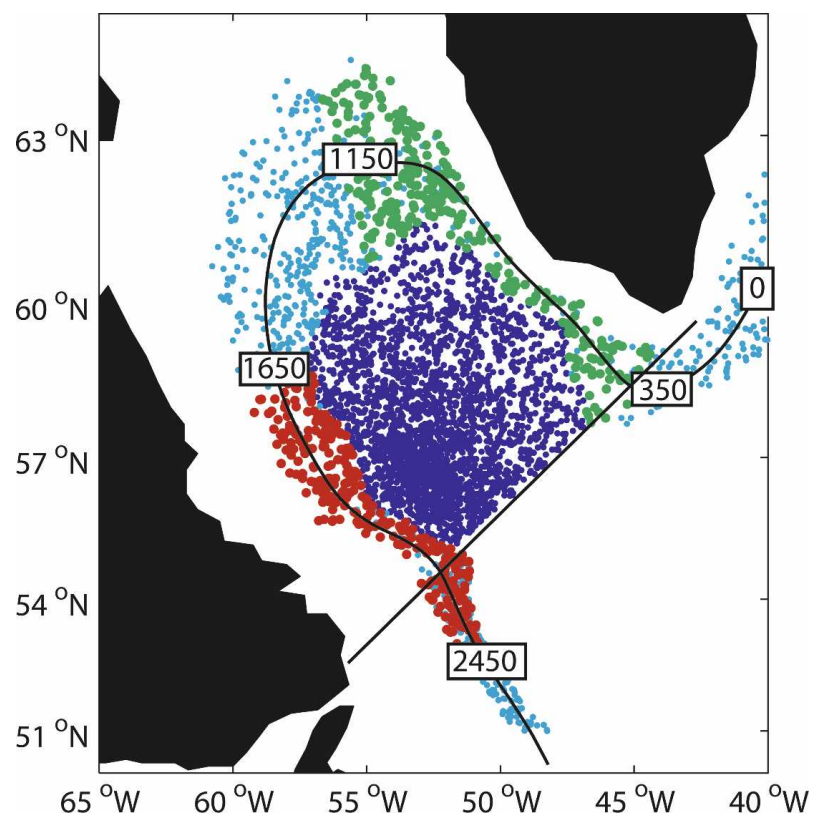

FIG. 3. The locations of all (P)ALACE float profiles used in this study. The color corresponds to the category in which the profile was placed, dark blue: interior Labrador Sea (water deeper than $3000 \mathrm{~m}$ ), green: the "entering boundary current," and red: the "exiting DWBC"; the light blue represents all profiles that are not included in a category, either because of their location or because they were removed during quality control. The black line is the smoothed $2500-\mathrm{m}$ isobath used to calculate the distance around the Labrador Sea, with several distances $(\mathrm{km})$ marked as guides. The southern boundary used throughout this analysis is also shown in black.

eastern (or "entering") DWBC, and the western (or "exiting") DWBC. Because convection is spatially and temporally variable, the distribution in space and time of the float profiles likely impacts our analysis, at least to some degree. However, there is little reason to suspect that the sampling of the waters is less representative in the interior compared to the boundary current, and, as such, we do not believe the float distribution systematically biases our comparison of convective activities among these regions.

As a convectively formed water mass, LSW is characterized by low vertical property gradients and can be traced from its formation region by a minimum in potential vorticity (PV), which is proportional to the vertical density gradient and tends to be preserved in the ocean's interior (Talley and McCartney 1982). In the past decade, two types of LSW have been described (Pickart et al. 1997; Stramma et al. 2004), distinguished by their densities: upper LSW (ULSW) bounded by the isopycnals $\sigma_{\theta}=27.68$ and 27.74 and deep or classical LSW (CLSW) bounded by $\sigma_{\theta}=27.74$ and 27.80 (Stramma et al. 2004).

Because LSW is characterized by a low vertical den- sity gradient, the water mass can be identified as the thickest pycnostad within a profile in the Labrador Sea. The criterion by which the thickest pycnostad is chosen is based on uniformity in density for any profile that extends to or below $700 \mathrm{~m}$. After smoothing the salinity profile with a four-point boxcar filter, removing all density inversions, and discarding profiles in which density inversions account for $20 \%$ or more of all observations, each profile is examined for all layers of uniform density within a threshold of $0.03 \mathrm{~kg} \mathrm{~m}^{-3}$. The thickest of these layers is considered the greatest pycnostad for each profile. The sensitivity of the pycnostad thickness to the total depth over which the floats profiled was small since the vast majority of pycnostad bottom depths is found to be shallower than the bottom depth of the profile. This approach, which chooses a pycnostad with regard only to vertical uniformity, allows the consideration of all thick or low-potential-vorticity (PV) water masses regardless of their specific density or depth. Additionally, handling the data in this way minimizes the influence of the conductivity meters, which are prone to drift over the lifetime of a float but are expected to be stable for the duration of a single profile.

A common approach to analyzing the (P)ALACE float data is to treat each profile and displacement as an independent observation of a CTD and current meter adrift in the ocean, then use averaging schemes to place the temperature, salinity, and velocities in a quasiEulerian frame (Lavender et al. 2005, hereafter L05; Straneo 2006a). The array bias, or error in the mean velocity field arising from the nonuniform launch locations of the floats, has been shown to be small relative to the mean velocity field (Straneo et al. 2003) and is therefore neglected in this analysis. Lavender et al. (2005) used an Eulerian averaging scheme to calculate the mean velocity field, geostrophically adjusted to the 700-m depth. We make use of this velocity field to calculate eddy heat fluxes $\left(v^{\prime} T^{\prime}\right)$ from the individual float displacement and temperature profiles, as schematized in Fig. 4a. These individual heat fluxes were then averaged within $1^{\circ}$ latitude by $0.5^{\circ}$ longitude grid $(\sim 50 \mathrm{~km}$ square) over time to deduce a mean field of eddy heat fluxes, $\overline{v^{\prime} T^{\prime}}$. To test whether these eddy fluxes were correlated with the temperature gradient, as would be expected for a downgradient eddy heat flux, the temperature gradient was rotated into coordinate axes aligned with the local mean flow and compared with the mean eddy heat fluxes after spatial smoothing. Although the floats do not record the eddy activity that occurs during the drift period of their cycle, they also do not integrate over that period, as would a dye tracer. Rather, each realization gives a float trajectory that is dependent on the eddy field at the time of the initial 
and final position fixes. We assume that the temporal average from all realizations within each grid box is a reasonable estimate of the eddy field. This assumption is only good where there are sufficient realizations to arrive at a robust mean. For most of the domain, there are more than 10 float displacements in each grid box, and the standard error of the estimate is less than half the mean. We are therefore confident about the sign of the eddy heat fluxes and their relative magnitudes over most of the domain.

For the calculation of the mean flow perpendicular to the isobath bounding the Labrador Sea, we use simple

a)

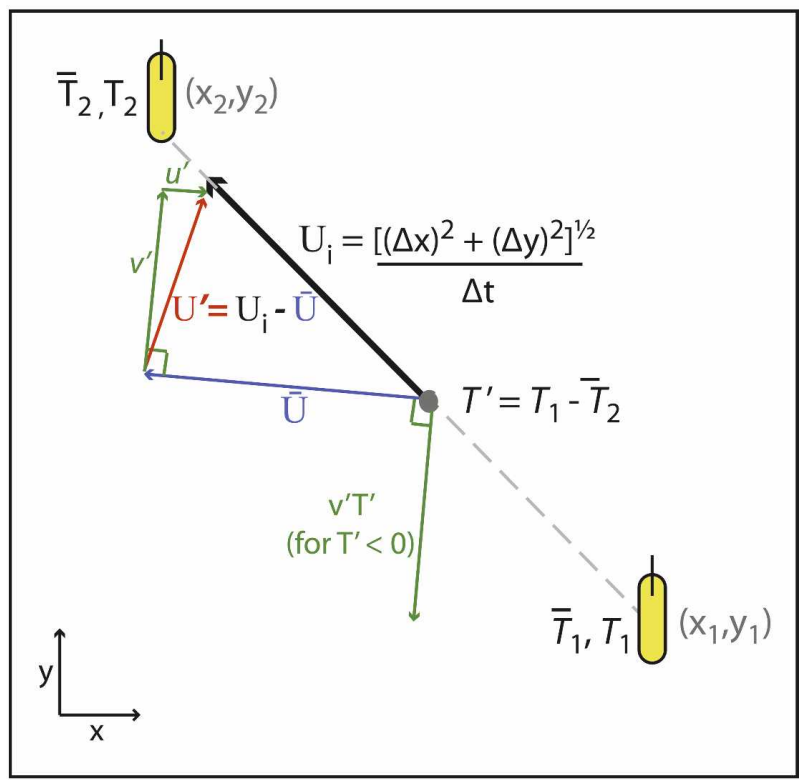

b)

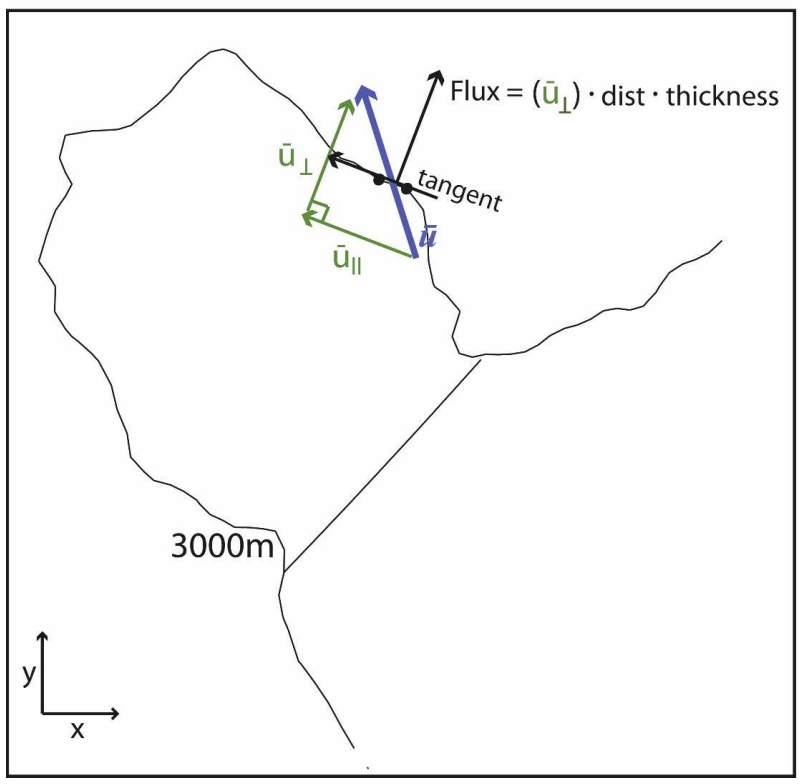

Eulerian averages of the velocity in $50-\mathrm{km}$ square bins, as opposed to the mean velocities calculated by L05. The objective analysis used by L05 assumes a correlation length scale that is greater along contours of equal water depth than across them, and such an assumption may influence the magnitude of the cross-isobath mean flow. In practice, however, our simple mean velocity fields are qualitatively and quantitatively very similar to those obtained by objective analysis, having an average velocity difference of approximately $1 \%$ from L 05 . These mean velocities are used to calculate the local volume flux across the $3000-\mathrm{m}$ isobath, as described in Fig. $4 \mathrm{~b}$. The $3000-\mathrm{m}$ isobath is determined from the 1-min bathymetric data from the British Oceanography Data Center, smoothed with a 25-min boxcar filter and then decimated to every 20th cell. The filter width was chosen to be comparable to an estimate of the internal Rossby radius of deformation, as discussed in Bower and Hunt (2000). We adopt a sign convention in which a negative flux corresponds to flow entering the interior and a positive flux to flow entering the boundary current region or exiting the southern boundary. These local fluxes are summed over the entire boundary to estimate the total volume flux from the interior Labrador Sea. To calculate an uncertainty associated with this total volume flux, a Monte Carlo approach is employed. The Monte Carlo approach draws velocities at

$\leftarrow$

FIG. 4. Schematics describing calculations of (a) $v^{\prime} T^{\prime}$ and (b) the volume flux perpendicular to the $3000-\mathrm{m}$ isobath. (a) A single float displacement (dashed gray line) is used to compute a velocity ( $\mathbf{U}_{i}$, black arrow). The mean velocity ( $\overline{\mathbf{U}}$, blue arrow) is interpolated from the gridded mean velocity field (L05) to the midpoint of the float displacement and subtracted from $\mathbf{U}_{i}$. The vector difference between $\mathbf{U}_{i}$ and $\overline{\mathbf{U}}$ ( $\mathbf{U}^{\prime}$, red arrow) is decomposed into along-mean flow $\left(u^{\prime}\right)$ and across-mean flow $\left(v^{\prime}\right)$ components (green arrows). The across-flow component is multiplied by the corresponding temperature anomaly to yield $v^{\prime} T^{\prime}$. The temperature anomaly is calculated as the difference between the $700-\mathrm{m}$ temperature at the start point of the displacement $\left(T_{1}\right)$ and the mean 700-m temperature at the end point $\left(\bar{T}_{2}\right)$. We subtract the mean temperature at the end point of the displacements so as to consider the advection of temperatures that are anomalous to their destination location. This process is repeated for every float displacement in the study area. (b) The $3000-\mathrm{m}$ isobath is contoured according to a basic contouring algorithm that employs a linear interpolation scheme between adjacent points. The mean velocity is interpolated from the gridded mean velocity field to the midpoints of two consecutive vertices on the contour line. These vertices are used to construct a local tangent to the isobath, and the mean flow at the midpoint is decomposed into its alongisobath and across-isobath components (green arrows). The across-isobath component is multiplied by the distance between the vertices and an assumed thickness so as to calculate a volume flux across the boundary. 

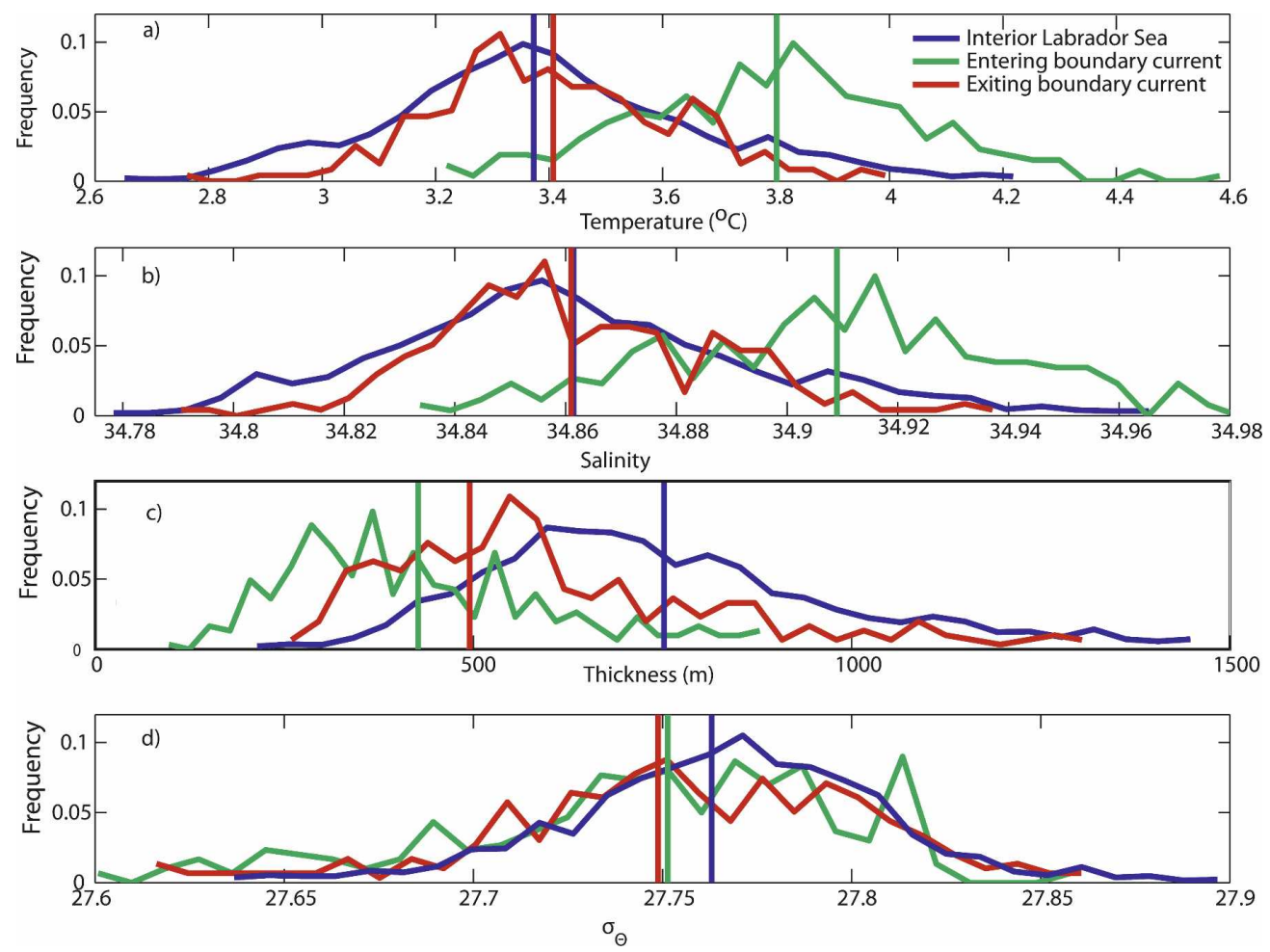

FIG. 5. Histograms of LSW properties in the interior Labrador Sea (blue), the entering boundary current (green), and the exiting DWBC (red): outliers (greater than three standard deviations from the mean) have been removed. (a) Temperature $\left({ }^{\circ} \mathrm{C}\right.$ ) and (b) salinity on the 27.74 isopycnal, (c) the thickness (m) of the greatest pycnostad, and (d) the potential density of the greatest pycnostad. The greatest pycnostad is chosen according to uniformity of the density profile (see section 2 for details). The frequency of the observation is expressed as a fraction of the total observations in each category. The geographic constraints on the profile category are shown in Fig. 3.

random from normal distributions with the same mean and standard deviation as our calculated mean velocities and then repeats all steps of the process described above until the cumulative mean of the calculation stabilizes, which required over 1000 iterations. This approach calculates the uncertainty of the cross-isobath velocity alone, which is then multiplied by a fixed LSW thickness to approximate a volume flux. The Monte Carlo approach was repeated with random draws from normal distributions of both the velocity field and the LSW thickness, as estimated by the height of the greatest pycnostad, described above. Both results are reported in section $3 \mathrm{c}$.

\section{Results and discussion}

A comparison of the mean properties in the outgoing DWBC to those in the incoming Irminger Current reveals a dramatic evolution of the boundary current as it circuits the Labrador Sea (Fig. 5). On the LSW isopycnal, the exiting DWBC is significantly cooler and fresher than the incoming Irminger Current. Likewise, the average thickness of the LSW is $70 \mathrm{~m}$ greater in the outgoing DWBC than in the incoming boundary current. Our study focuses on the mechanisms that control this evolution, whether it is the result of heat loss directly from the boundary current or the advective/ diffusive flux of LSW from the interior Labrador Sea. Understanding these mechanisms may also shed light on a source of interannual variability of the exported LSW properties, as each is likely to transform the boundary current at a different rate. For example, some of the dense water formed in the convective interior of the basin apparently never enters the boundary current, as evidenced by the slight but significantly cooler, fresher, and thicker LSW in the interior than the exiting DWBC (Fig. 5). Furthermore, L05 estimate that the 27 floats that operated continuously for more than 200 days spent an average of more than $1.5 \mathrm{yr}$ in the Labrador Sea before exiting or failing, implying a residence time for the basin of more than one year. Thus, the LSW formed in any given winter is not fully exported 
from the basin, and the mechanisms by which it enters the boundary current may impact the rate at which it exits the Labrador Sea and its downstream signal.

\section{a. Formation of $L S W$ in the boundary current}

The wind-driven, barotropic Deep Labrador Current, which resides over the midslope of the Labrador Sea near the 3000-m isobath, may seem an unlikely location for LSW formation, as it receives a constant advective source of relatively warm, salty, and stratified Irminger Sea Water. Nonetheless, a hydrographic cruise in February-March 1997 captured the formation of LSW on the slope in the region of the DWBC (Pickart et al. 2002). At the end of that March, mixed layers roughly $1400 \mathrm{~m}$ deep with densities as high as $\sigma_{\theta}=$ 27.76 were observed shoreward of the $3000-\mathrm{m}$ isobath on the western side of the Labrador Sea. To understand the upstream Lagrangian history and downstream fate of the mixed layers in the boundary current, we analyze the pathways and profiles of the (P)ALACE floats in the boundary current.

Almost 20 (P)ALACE floats circuited the Labrador Sea in a single year or less, moving swiftly in the boundary current, shoreward of the $3000-\mathrm{m}$ isobath. A handful of these exhibited deep convection during their transit; we have chosen float number f0196 as a representative to illustrate the possibility of LSW formation directly in the boundary current in the final year of its lifetime, 2001-02. This float was released in the Irminger Sea in the summer of 1997 and first drifted into the Labrador Sea with the Irminger Current that fall. From there, it entered the eastern corner of the Labrador Sea where it remained for almost $2 \mathrm{yr}$ and then looped anticyclonically back toward its release location. In September 2001 the float rounded the southern tip of Greenland once more before swiftly tracing a $2200-\mathrm{km}$ cyclonic circuit of the Labrador Sea in only eight months. The profiles observed during this final circuit of the Labrador Sea are shown in the waterfall plot of Fig. 6. The profile taken as the float first rounded the southern tip of Greenland is highly stratified with surface densities as low as $\sigma_{\theta}=27.5$. At this time, the pycnostad bounded by the $\sigma_{\theta}=27.73-27.76$ isopycnals was centered at a depth of $1000 \mathrm{~m}$ and was only $100 \mathrm{~m}$ thick (Fig. 6).

The onset of cooling and mixing is apparent in the last two profiles taken in 2001, as a shallow mixed layer of approximately $100 \mathrm{~m}$, with a density of $\sigma_{\theta}=27.6$, was formed (Fig. 6b). As winter progressed and the float traveled in the slower, wider boundary current on the northern rim of the Labrador Sea, the mixed layer continued to deepen, clearly mixing from the top down as the stratification was destroyed over the entire 1200-m profile. The most dramatic increase in mixed layer depth occured in February and March when the float completed a small anticyclonic loop during which it crossed the 3000-m isobath for the first time. As the column started to restratify in April, the float's conductivity meter malfunctioned, and, by the end of May, the float stopped reporting its position to the satellite. In less than eight months, primarily in the boundary current of the Labrador Sea, this float recorded the formation of a $1000-\mathrm{m}$ mixed layer as the water column cooled $1.5^{\circ} \mathrm{C}$ from its initial average temperature upon entering the Labrador Sea (Fig. 6d). The cumulative heat loss for the water column along the path of the float was $6 \mathrm{GJ} \mathrm{m}^{-2}$, more than twice the average annual heat content loss in the central Labrador Sea over the float years (Straneo 2006a). Four additional floats exhibited behavior similar to this one, with each subsequent profile exhibiting a progressively deeper mixed layer as the float traveled in the boundary current region. Like float f0196 (Fig. 6), one of the four shows the greatest heat loss while traveling at a reduced rate near the 3000-m isobath. The other three show the formation of deep mixed layers on profiles straddling large displacements, presumably as the floats travel in the high velocity region of the boundary current. For brevity, we show only the trajectory and profiles of one float.

The heat loss in the boundary current, illustrated by the pathway and profiles of a single float, can be more thoroughly explored by considering all of the profiles taken within the boundary current region, as defined by the 1000- and 3000-m isobaths (Lavender et al. 2000). Figure 7 shows the space-time evolution of pycnostads in the boundary current. The advection of the floats by the boundary current is apparent in the slope of the points, which approximates the mean speed of the boundary current. Those pycnostads found within $50 \mathrm{~m}$ of the surface (outlined in black) are most likely formed locally and recently, as suggested by the minimal surface stratification.

One of the most salient features of the scatterplot is the rapid decline in pycnostad thickness in the boundary current region after the winter of 1997/98. The year 1997 is considered the transition year between the intense convection of the early 1990s and the restratification period of the late 1990s (Lazier et al. 2002; Pickart et al. 2002). Following the $1997 / 98$ season, mild winters caused shallow convection and isolation of the deeper CLSW from further ventilation (Lazier et al. 2002). According to Kieke et al. (2006), this decrease in deep convection and shutdown of CLSW formation after 1997 corresponded with an increase in the thickness 
a)
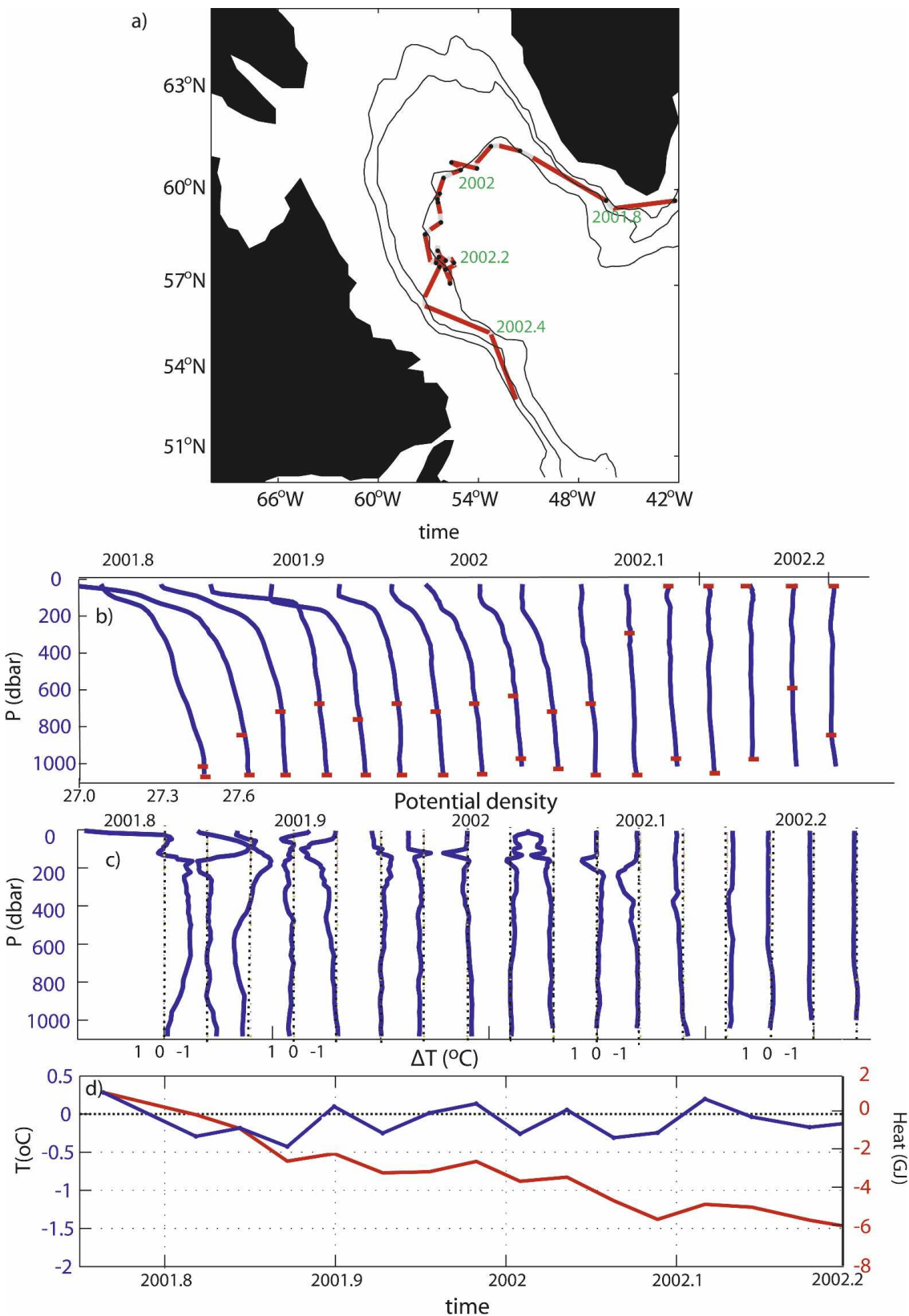

FIG. 6. Quasi-Langrangian characteristics of float f0196 during its final circuit of the Labrador Sea. (a) The float's trajectory from September 2001 to May 2002. Red parts of the trajectory are the displacements of the float at its drifting depth of approximately $1200 \mathrm{~m}$; gray lines show the surface drift while the float communicated with the satellite; black dots are the profile locations. Contours are bathymetry, as in Fig. 2. (b) A waterfall plot of the density during the float's final circuit (small density inversions are caused by the low precision of the conductivity meter). The red hatches mark the 27.73 and 27.76 isopycnals; in profiles in which the hatch marks fall at the bottom (top) of the profile, there is no density greater than 27.76 (less than 27.73). (c) Temperature difference between subsequent profiles (previous profile subtracted from current profile) as a function of pressure. The dotted black lines show zero temperature change. (d) Change between subsequent profiles in temperature (left vertical axis) and heat content (right vertical axis) integrated over the top $1000 \mathrm{~m}$ of each profile (blue) and cumulative change over the float's final circuit of the Labrador Sea (red). Because the float's conductivity meter malfunctioned before the float stopped transmitting its position to the Argos satellite system, the last profile on the waterfall plots is from February 2002, while the last position on the trajectory plot is from May 2002. 


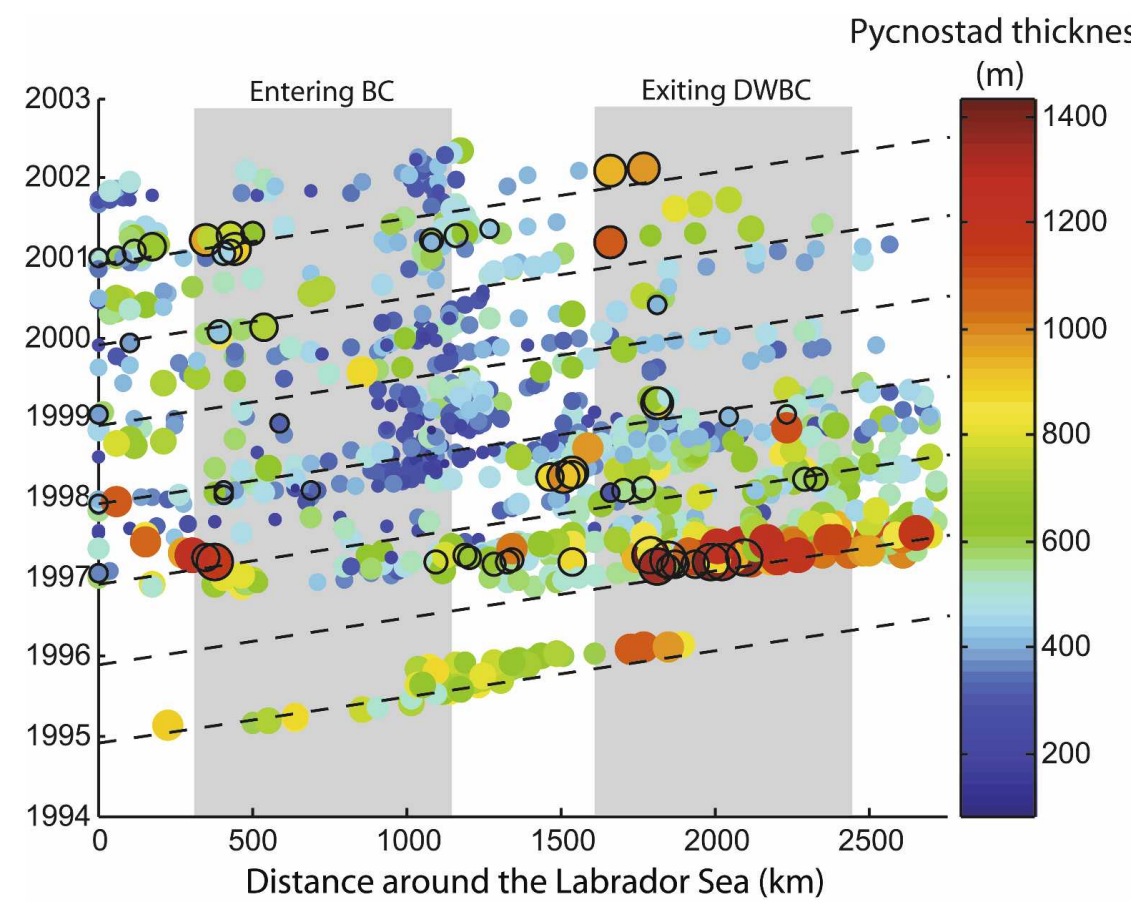

FIG. 7. The date of each profile in the boundary current region vs its distance around the Labrador Sea, as calculated for Fig. 3 (gray bars correspond to the boundary current regions designated as "entering boundary current" or "exiting DWBC," as in Fig. 3). The size and color of the markers are proportional to the thickness of the profile's thickest pycnostad. Black circles around the marker indicate a pycnostad within $50 \mathrm{~m}$ of the sea surface. Dashed lines indicate the mean speed of the boundary current $\left(5.4 \mathrm{~cm} \mathrm{~s}^{-1}\right)$.

of the less-dense ULSW layer, as defined by the depth between two bounding isopycnals $\left(\sigma_{\theta}=27.68\right.$ and 27.74), which was then shown to spread along similar pathways as CLSW. Our analysis shows that, following 1997, the thickness of layers with great vertical uniformity is much reduced throughout the boundary current region. This lack of vertical uniformity suggests that the ULSW is more stratified than the CLSW of the earlier years.

A second interesting feature in Fig. 7 is the presence of deep mixed layers formed in the boundary current region by the southeastern tip of Greenland. Many of these mixed layers are coincident in both space and time with a tip jet convection event that has been modeled (Pickart et al. 2003a) and observed in hydrographic surveys in February 1997 (Pickart et al. 2003b) and are consistent with the hypothesis that some LSW may actually be formed in the Irminger Sea (Pickart et al. 2003b). It is worth noting, however, that the mixed layers formed in this tip jet region in January through March of 1997, 1998, and 2001 do not seem to penetrate into the Labrador Sea in the boundary current. A likely fate of these pycnostads is entrainment into a localized, cyclonic recirculation cell near the southern tip of
Greenland that diverts the freshly convected water mass offshore and eastward back to the Irminger Basin, possibly precluding its direct entrainment into the DWBC (Lavender et al. 2002; L05; Straneo et al. 2003).

Finally, it is of interest to consider the floats that escaped the Labrador Sea in 1997: those between 2000 and $2500 \mathrm{~km}$ (the southern boundary of the Labrador Sea and Orphan Knoll). Here the pycnostads, which appear to have been formed at least in part within the boundary current, thin only slightly with distance away from the Labrador Sea, maintaining a thickness of more than $1000 \mathrm{~km}$ as they exit the Labrador Sea. A 1000-m pycnostad of uniform density within a threshold of $0.03 \mathrm{~kg} \mathrm{~m}^{-3}$ translates to a PV of $4 \times 10^{-12} \mathrm{~m}^{-1} \mathrm{~s}^{-1}$, similar to the PV signature traditionally used to trace the water mass from its source (Talley and McCartney 1982). We did not extend this analysis beyond Orphan Knoll since there are relatively scarce observations shoreward of the 3000-m isobath and equatorward of Orphan Knoll. The winter of 1996/97 illustrates that LSW can be formed in the boundary current, exported from the Labrador Sea shortly thereafter, and maintain a thickness in excess of $1000 \mathrm{~m}$ as it is advected downstream at least $500 \mathrm{~km}$ from the southern boundary of 
the Labrador Sea. Many of the (P)ALACE floats eventually reenter the Labrador Sea and, on the whole, do not ultimately support an export pathway from the subpolar gyre into the subtropical gyre, possibly as a result of sampling issues and/or temporal variability (L05). Furthermore, these floats, operating over only 5 years, cannot confirm whether LSW formation in the boundary current is a regular event or, instead, happens infrequently, perhaps in intensely convective years. Nonetheless, this analysis suggests that LSW formed in the boundary current appears to be on a fast track to export from the Labrador Sea, a necessary, if not sufficient, step for eventual export from the subpolar gyre. The freshly convected pycnostads formed in the DWBC are advected past the southern boundary of the Labrador Sea within one to several months (Fig. 7).

\section{b. Eddy flux of LSW}

The second mechanism, an eddy advective flux moving LSW laterally into the DWBC, has been explored using numerical models (Katsman et al. 2004; Pickart et al. 1997; Straneo 2006b) and observational data (Pickart et al. 1996; Straneo 2006a). Here we build on these studies by using float velocity and temperature information to first explore spatial and seasonal variability in the eddy exchange in the Labrador Sea, then to quantify the eddy exchange of heat between the interior Labrador Sea and the DWBC, and finally to compare this flux to the mean advective heat flux and loss directly from the boundary current over the float years. Because the wind-driven boundary current that carries relatively warm, salty water from the Irminger Sea is found between the 1000- and 3000-m isobath (L05), exchange between the central Labrador Sea and the boundary current can be qualitatively explored by examining maps of the float exchange across the 3000-m isobath (Fig. 8). In this analysis, we use only the float displacements that occur at depth and exclude the surface displacements taken while the floats communicate with the satellite.

Surprisingly, these maps show a relatively even exchange of floats around the perimeter of the Labrador Sea, despite a well-known local maximum in eddy kinetic energy (EKE) on the eastern side of the gyre (Fratantoni 2001). On the other hand, the exchange, which seems to be fairly symmetrical in space, is less so in time: $50 \%$ more crossings of the $3000-\mathrm{m}$ isobath observed in winter than in summer. However, caution must be exercised in interpreting both the spatial and temporal patterns of float exchange between the boundary and central Labrador Sea. The float launch locations were concentrated in the western part of the central Labrador Sea, possibly affecting the spatial patterns of the isobath crossings. Additionally, many of the floats had shorter programmed drift times in winter and spring than in summer and fall, resulting in shorter and more numerous displacements (Fischer and Schott 2002). The impact of the shorter displacements on observed isobath crossings is not clear, but may increase the probability of observing exchange in winter relative to summer. Indeed, the ratio of the number of float displacements that cross the isobath to the number of float displacements within $100 \mathrm{~km}$ of the isobath shows little variation with time of year or distance around the Labrador Sea (Figs. 8a,b). However, there is a slight suggestion of a higher ratio of crossings to total observations both in the winter (Fig. 8a) and in the northeast corner of the basin (Fig. 8b), coincident with the location of the EKE maximum (L05).

To explore quantitatively the patterns of eddy exchange inferred from Fig. 8, the eddy heat flux is calculated. Although an eddy flux of potential vorticity would be the clearest indicator of downgradient flux of LSW, the floats do not sufficiently resolve the mean salinity field, and thus the mean density field, for this type of analysis. Therefore, the analysis here is focused on the eddy exchange of heat, $\overline{v^{\prime} T^{\prime}}$. Cross-stream eddy heat fluxes decrease lateral gradients in temperature, and are expected to warm the central Labrador Sea and cool the boundary current.

The mean eddy heat fluxes are plotted as vectors in Fig. 9a. The coordinate system used to construct Fig. 9 is aligned with the local mean flow such that the crossstream velocity is positive in a right-handed sense with respect to the mean flow. Thus, for most of the domain, in which the flow is predominantly cyclonic, the positive cross-stream velocity is pointed toward the interior Labrador Sea and the negative pointed outward toward the boundary current. The mean temperature field at $700 \mathrm{~m}$, which is shown as colors in Fig. 9a, suggests a horizontal temperature gradient pointing outward from the interior Labrador Sea. Therefore, a down-gradient eddy heat flux, $\overline{v^{\prime} T^{\prime}}$, in this domain should point inward toward the central Labrador Sea. Indeed, the eddy heat fluxes tend to point toward the interior Labrador Sea, suggesting a net flux of cold water to the boundary current and warm water to the interior (Fig. 9a). As expected, these eddy fluxes are acting against the temperature gradient and are maximized where the temperature gradient is greatest. This result is confirmed in Fig. 9b, which shows the highly significant negative correlation between the eddy heat fluxes and the temperature gradient. Furthermore, the eddy fluxes are greatest on the eastern side of the gyre, where EKE has been 
a)
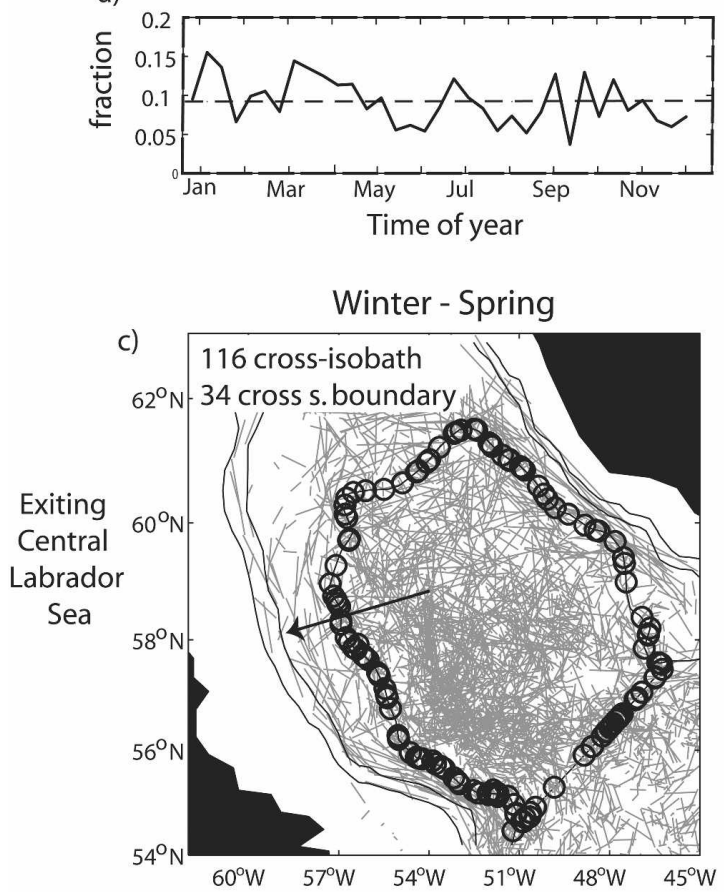

e)

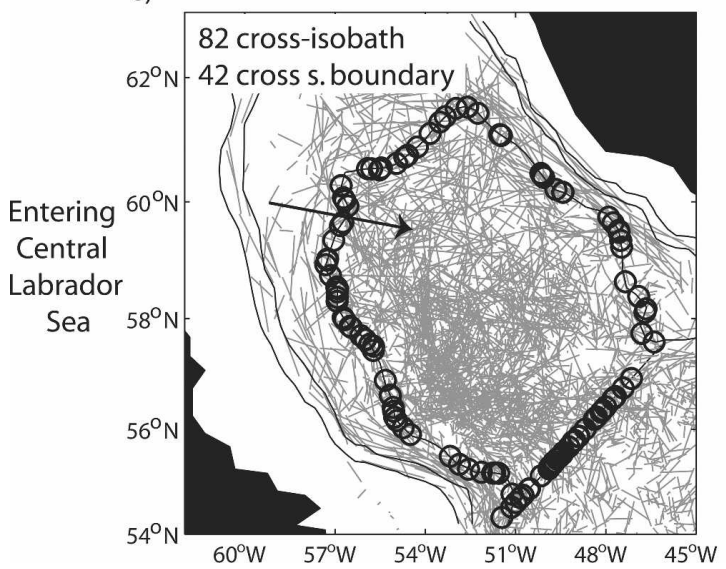

b)
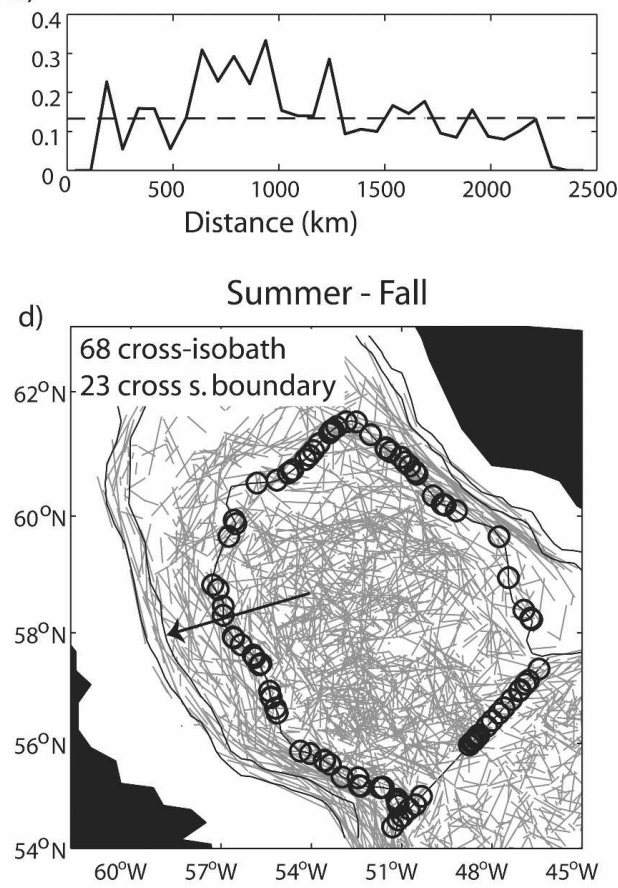

f)

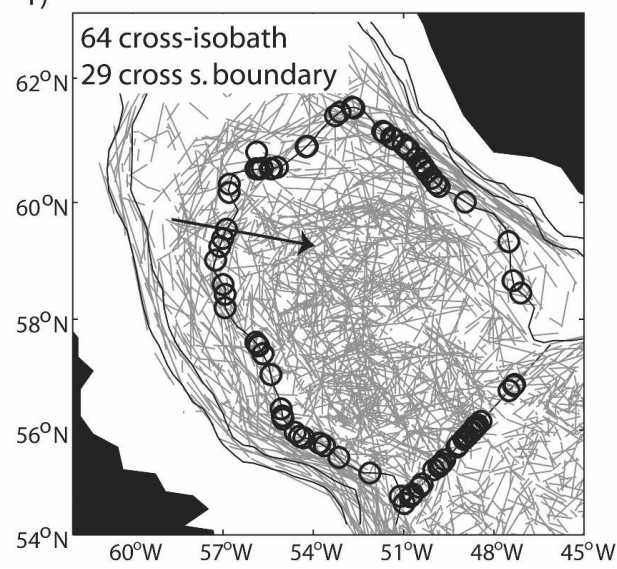

FIG. 8. Characteristics of float exchange across the 3000-m isobath. (a) Fraction of all float displacements within $100 \mathrm{~km}$ of the 3000-m isobath in a given month that cross the isobath that same month vs time of year. (b) Fraction of all float displacements within $100 \mathrm{~km}$ of a discrete point on the $3000-\mathrm{m}$ isobath that cross the isobath between that point and the next vs distance around the $3000-\mathrm{m}$ isobath. The distance scale on this plot is slightly different than the one shown in Fig. 3, as necessitated by the use of the 3000-m isobath in this analysis. The broad peak in the ratio of isobath crossings to total float displacements between 500 and $1000 \mathrm{~km}$ is in the northeast corner of the basin. (c)-(f) Float exchange across the 3000-m isobath and a southern boundary by season and direction, according to the labels on each column and row of maps (circles show the location at which an individual float crossed the isobath or southern boundary). Gray lines show the individual float displacements while the floats are at their target drifting depth. Contours are bathymetry, as in Fig. 2.

shown to be maximized. It is interesting to note that this pattern of intensified eddy exchange emerges in the $\overline{v^{\prime} T^{\prime}}$ field despite the reasonably symmetrical exchange of floats suggested by Fig. 8. This asymmetry is caused by a combination of stronger temperature anomalies and swifter velocity anomalies, as the region of high $\overline{v^{\prime} T^{\prime}}$ is coincident with both the steepest temperature gradient and high perturbation velocities $\left(\overline{v^{\prime 2}}\right.$, not shown).

In the absence of external sources and sinks of heat, 
a)

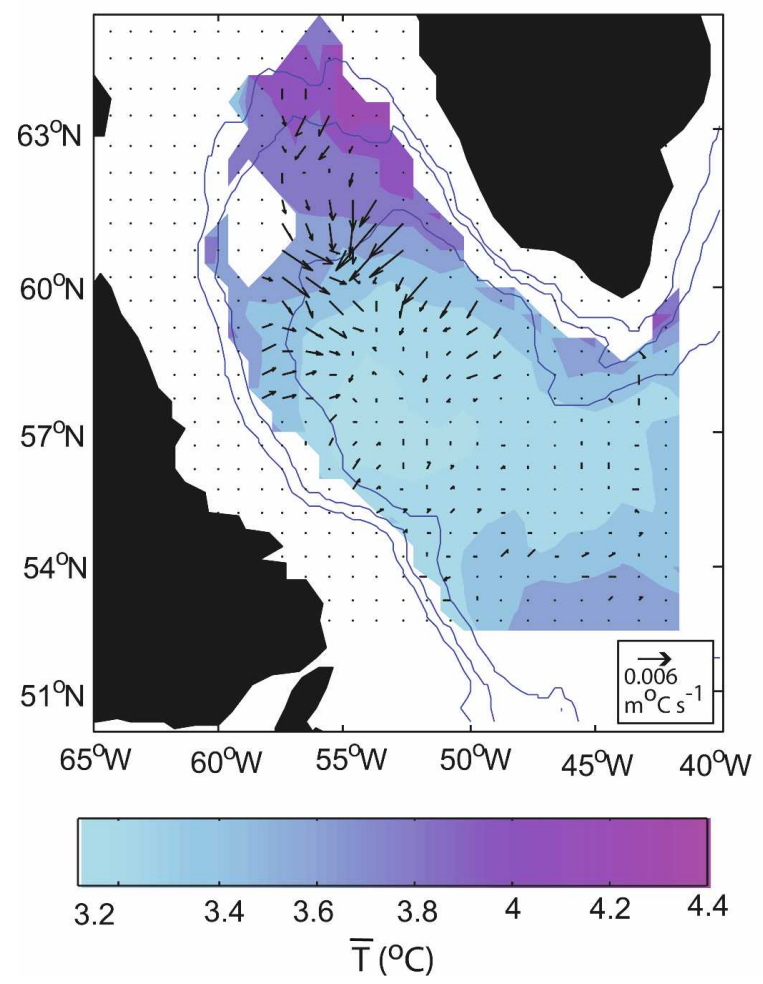

b)

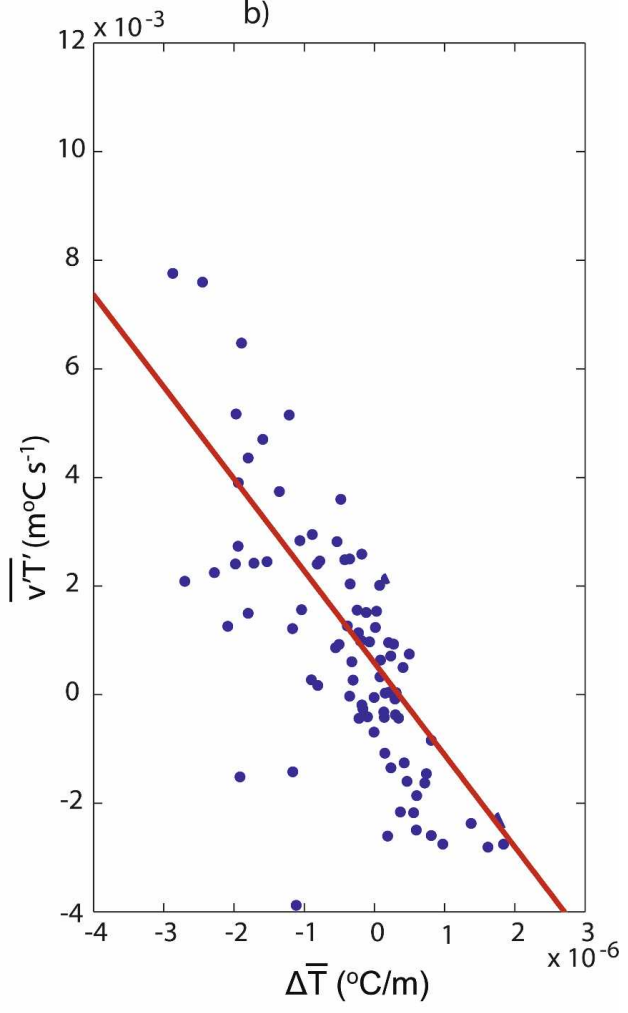

FIG. 9. (a) The cross-stream eddy heat flux, $\overline{v^{\prime} T^{\prime}}$ (the vector field). The mean temperature at $700 \mathrm{~m}$ is shown in colors. Contours are bathymetry, as in Fig. 2. (b) Cross-stream eddy heat flux vs the corresponding cross-stream temperature gradient $\left(r^{2}=0.48\right)$ for the area north of the southern boundary used throughout this analysis. Both the temperature gradient and the eddy heat flux have been smoothed at roughly $100 \mathrm{~km}^{2}$.

the divergence of the eddy heat flux would be the sole factor that could change the temperature of a Lagrangian parcel in the boundary current, according to the conservation equation

$$
\overline{D T}=\nabla \cdot \overline{v^{\prime} T^{\prime}}
$$

A simple scale analysis of this conservation equation sheds light on the size of the total eddy heat flux from the boundary current. An eddy heat flux of $3 \times 10^{-3} \mathrm{~m}$ ${ }^{\circ} \mathrm{C} \mathrm{s}^{-1}$, which is representative for the boundary current region from this analysis, removes $0.6^{\circ} \mathrm{C} \mathrm{yr}^{-1}$, given an assumed length scale of $100 \mathrm{~km}$, approximately the width of the boundary current. Given that the mean time a water parcel spends in the boundary current is roughly one year, this can be considered an estimate of the cooling that a parcel of water in the boundary current is expected to suffer due to eddy exchange alone. The scale of this eddy heat flux is of the same order as the heat gain due to eddies in the central Labrador Sea deduced by Straneo (2006a). For a range of pycnostad thicknesses from 250 to $1000 \mathrm{~m}$ over which this eddy flux may act, the total annual heat loss is $0.6-2.4$ GJ $\mathrm{m}^{-2}$ due to eddy exchange alone. This estimate of eddy heat exchange is very much in agreement with Straneo's (2006a) estimate of the total heat gain during an annual cycle in the central Labrador Sea, deduced from station data and float data to be approximately 2 GJ $\mathrm{m}^{-2}$.

\section{c. LSW is advected with the mean flow into the boundary current}

The third mechanism for export is that a horizontally divergent mean flow advects recently formed LSW into the DWBC at depth. The maps of float exchange between the central Labrador Sea and the boundary current (Fig. 8) reveal that floats are more frequently observed leaving the central Labrador Sea than entering. Over the course of all float years, $11 \%$ more floats are observed crossing the $3000-\mathrm{m}$ isobath as they exit the central Labrador Sea than as they enter, and the difference approaches $21 \%$ for the winter and spring months alone. The net loss of floats from the interior is consistent with a horizontal mass divergence at the 


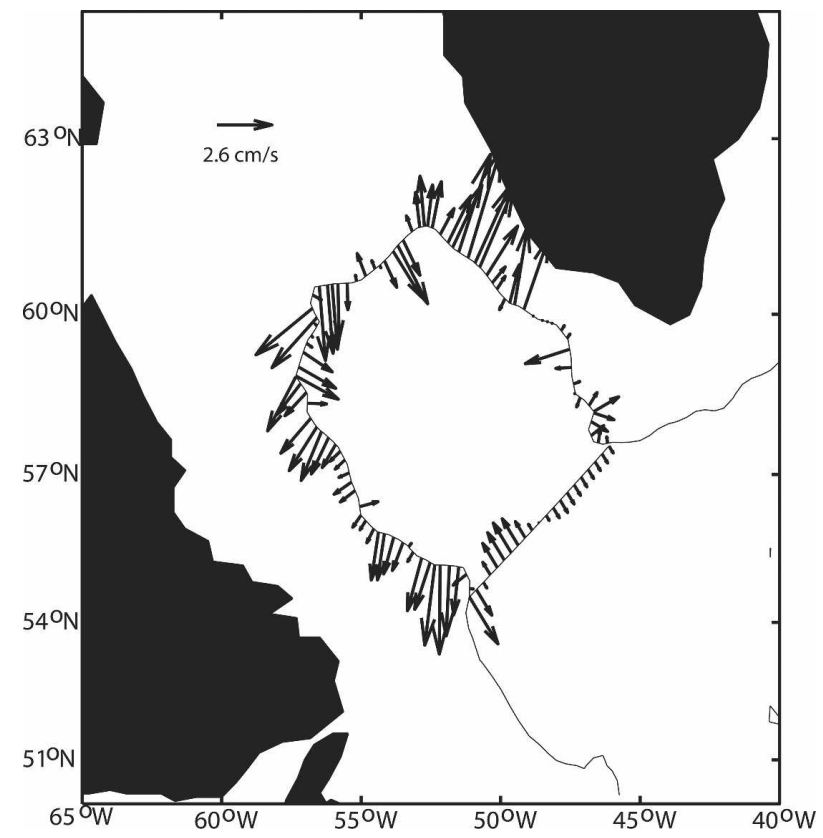

FIG. 10. The mean velocity perpendicular to the $3000-\mathrm{m}$ isobath, constructed as described in the Fig. 4b schematic.

mean depth of the floats. Because the divergence of the mean velocity field, $\boldsymbol{\nabla} \cdot \overline{\mathbf{u}}$, is noisy and difficult to interpret, we instead investigate the divergence of the mean flow by calculating the total volume flux from the interior Labrador Sea (see section 3 for details).

For consistency, we present the volume flux across the 3000-m isobath and the southern boundary used throughout this study, though the result is qualitatively similar regardless of the exact isobath chosen as the boundary. We also repeated the analysis bounding the region with several contours of PV $(f / h$, where $f$ is the Coriolis parameter and $h$ is the total water column depth), with similar results. The velocity perpendicular to the $3000-\mathrm{m}$ isobath is almost everywhere outward, consistent with the exchange maps (Fig. 8) that demonstrated a net loss of floats from the interior Labrador Sea across this boundary. Very sluggish flow crossing the southern boundary reflects the presence of a weak anticyclonic recirculation there, noted by $\mathrm{L} 05$. The strongest cross-isobath flow is in the northeast where the steep topography that constrains the flow takes a sharp turn and produces a local maximum in EKE (Fratantoni 2001; L05). The overall pattern is reminiscent of the LSW spreading pathways deduced by Straneo et al. (2003) using an advective-diffusive model constrained by the float velocities. A total volume flux for the region shown in Fig. 10 is calculated by multiplying the perpendicular velocities by a horizontal length scale and again by a vertical distance over which the mean flow is assumed to be valid. For an assumed thickness of $250 \mathrm{~m}$, the total volume flux is $4.3( \pm 3.8) \mathrm{Sv}$ $\left(\mathrm{Sv} \equiv 10^{6} \mathrm{~m}^{3} \mathrm{~s}^{-1}\right)$ from the interior to the boundary current. The uncertainty given here is one standard deviation, as calculated by a Monte Carlo method. The estimate of the outward volume flux is much greater, as is the corresponding uncertainty, when the perpendicular velocity is multiplied by the estimate of pycnostad thickness, as calculated from the float profiles. Incorporating the pyncostad thickness estimates into the Monte Carlo approach for estimating the volume flux results in an estimated $11( \pm 9)$ Sv entering the boundary current from the interior Labrador Sea. Though both flux estimates are only slightly larger than the uncertainty, it does suggest an outward mean flux within error of estimates suggested by a previous study (Pickart and Spall 2007). This outward volume flux implies that LSW transfer from the interior to the boundary current may occur not only as a property exchange facilitated by eddies but also as an advected phenomenon.

The approximate magnitude of the advective heat flux can be evaluated by examining $\overline{\mathbf{u}} \cdot \nabla \bar{T}$, the crossisobath velocity multiplied by the local temperature gradient. With a mean cross-isobath flow recorded by the floats of only $1.5 \mathrm{~cm} \mathrm{~s}^{-1}$ and a temperature gradient of roughly $10^{-3}{ }^{\circ} \mathrm{C} \mathrm{km}^{-1}$, the advective flux from the interior to the boundary current could cool the boundary current by approximately $0.4^{\circ} \mathrm{C} \mathrm{yr}^{-1}$, approximately as much as that estimated from the eddy flux. For the same range of pyncostad thickness $(250-1000 \mathrm{~m})$ over which this advective flux may reasonably be expected to act, the total annual heat lost from the boundary current is $0.25-1.0 \mathrm{GJ} \mathrm{m} \mathrm{m}^{-2}$. This outward heat flux is between $12 \%$ and $50 \%$ as large as the total heat gain in the interior, as deduced by Straneo (2006a).

To balance an outward volume flux, a comparable inward flux is expected, presumably of warmer, more stratified water at the surface. To evaluate such a flux, we performed an identical analysis using a mean velocity field calculated from surface drifter data (Pazan and Niiler 2004). The result of this analysis is inconclusive as the estimate of the volume flux for the surface flow was only half as big as the estimate of the error, even when using the velocities derived from the entire historical drifter dataset (1989-2005). This is not surprising, given that the drifter-derived mean surface velocities are smaller than the standard error of the estimate for much of the Labrador Sea (Fratantoni 2001). The question of divergence of the mean flow at depth balanced by surface convergence is thus not fully resolved by the available data, but is suggested by this analysis and warrants further investigation. 
TABLE 1. Estimated heat losses from the boundary current during its circuit of the Labrador Sea. The loss directly from the boundary current is estimated from ECMWF heat fluxes in the Labrador Sea between the 1000- and 3000-m isobaths, integrated over an annual cycle. The estimates of the eddy heat flux and advective heat flux are described in sections $3 b$ and $3 c$.

\begin{tabular}{lc}
\hline \multicolumn{1}{c}{ Source } & Heat loss $\left(\mathrm{GJ} \mathrm{m}^{-2} \mathrm{yr}^{-1}\right)$ \\
\hline Loss directly from boundary & $1-2$ (ECMWF); 6 (along the \\
current & path of float f0196) \\
Eddy heat flux, $\overline{v^{\prime} T^{\prime}} / L$ & $0.6-2.5$ \\
Advective heat flux, $\overline{\mathbf{u}} \cdot \nabla \bar{T}$ & $0.2-1.0$ \\
\hline
\end{tabular}

\section{d. Interannual variability of $L S W$ properties}

Each of the three proposed mechanisms examined above has been shown to play a role in transforming the properties of the boundary current as it transits the Labrador Sea. The estimated magnitudes of the heat fluxes, summarized in Table 1, demonstrate that all mechanisms are of approximately equal importance in setting the mean properties of the LSW that exits the region via the DWBC. A separate question remains, however, as to the mechanism that is responsible for the temporal variability of the exported LSW. To address this question, we next consider how these mechanisms vary interannually over the float years and how these variations compare with other sources of variability, such as heat exchange with the atmosphere and changes in the incoming source water. In other words, can the temporal variability of the exported LSW be traced to the temporal variability of the source waters from the Greenland Sea, the variability of the eddy heat exchange, variability of buoyancy forcing in the interior Labrador Sea, and/or variability of buoyancy forcing in the boundary current region?

To answer this question, temperature time series on the $\sigma_{\theta}=27.74$ isopycnal were constructed for the inflowing waters, the exiting waters, and the Labrador Sea interior (Fig. 11a). These time series were constructed for several density surfaces in the LSW range (not shown), with similar temporal variability in every case. Over the course of the float years, the temperature of LSW is most variable in the exiting DWBC, as compared with the interior Labrador Sea and the incoming boundary current (Fig. 11a). Between 1996 and 1997 , the temperature on the 27.74 isopycnal drops $0.4^{\circ} \mathrm{C}$ in the exiting DWBC while staying nearly constant in the entering boundary current and slightly increasing in the interior. The relative stability of the temperature in the incoming boundary current and interior Labrador Sea suggests that variability of the incoming source waters and interior convection had little effect on the properties of the outgoing water mass in
1997, and we are left to examine the role of fluxes from the central Labrador Sea and atmospheric heat loss directly from the boundary current.

The exchange between the interior Labrador Sea and the exiting DWBC may vary as a result of changes in advective fluxes and/or eddy exchange. In any given year, the float trajectory data do not resolve a mean velocity field with enough certainty to study interannual variability of the mean advective heat fluxes. However, individual eddy heat fluxes, $v^{\prime} T^{\prime}$ (calculated by differencing the mean velocity and temperature fields from individual float displacements, as in the schematic of Fig. 4a), can shed light on the interannual variability in the strength of eddy heat exchange. By averaging each $\left|v^{\prime} T^{\prime}\right|$ over the whole domain for each year, we have created an index of the strength of eddy exchange (Fig. 11b). Because this index is calculated as an average of the absolute value of all the fluxes over the whole domain, it is qualitatively and quantitatively different than the mean eddy heat flux explained in section $3 \mathrm{~b}$. The time series of this index shows that eddy exchange was considerably stronger in 1996 and 1997 (Fig. 11b) than during the subsequent 4 years. The vigorous exchange in 1996 corresponds with the greatest temperature difference between the exiting DWBC and the interior Labrador Sea and should act to reduce that gradient. The exchange continues to be strong in 1997, the year that the temperature drops in the boundary current. However, in this year, the temperature of the LSW isopycnal in the exiting DWBC drops below the temperature in the interior (Fig. 11a). Therefore, the downgradient eddy exchange is not likely to be responsible for this great temperature drop. Instead, convection directly from the boundary current is a more likely suspect. A viable alternative hypothesis is that the boundary current temperature reflects the intense convection and cold LSW production that occurred in the interior Labrador Sea prior to 1997, as suggested by an anonymous reviewer, based on results from a moored array of instruments in the DWBC and interior Labrador Sea (Dengler et al. 2006; Fischer et al. 2004). The time series from the moored array shows that both the interior and DWBC are warming over the period 19972005, with the DWBC slightly cooler than the interior during this time. Therefore, it is plausible that the boundary current contains a cooler interior LSW product, formed during the deep, intense convection of the early 1990s. Neither the moored array nor the floats provide sufficient data to conclude which hypothesis is correct. Here, we explore the possibility that heat loss directly from the boundary current accounts for the observed temperature gradient.

Convection directly in the boundary current appears 

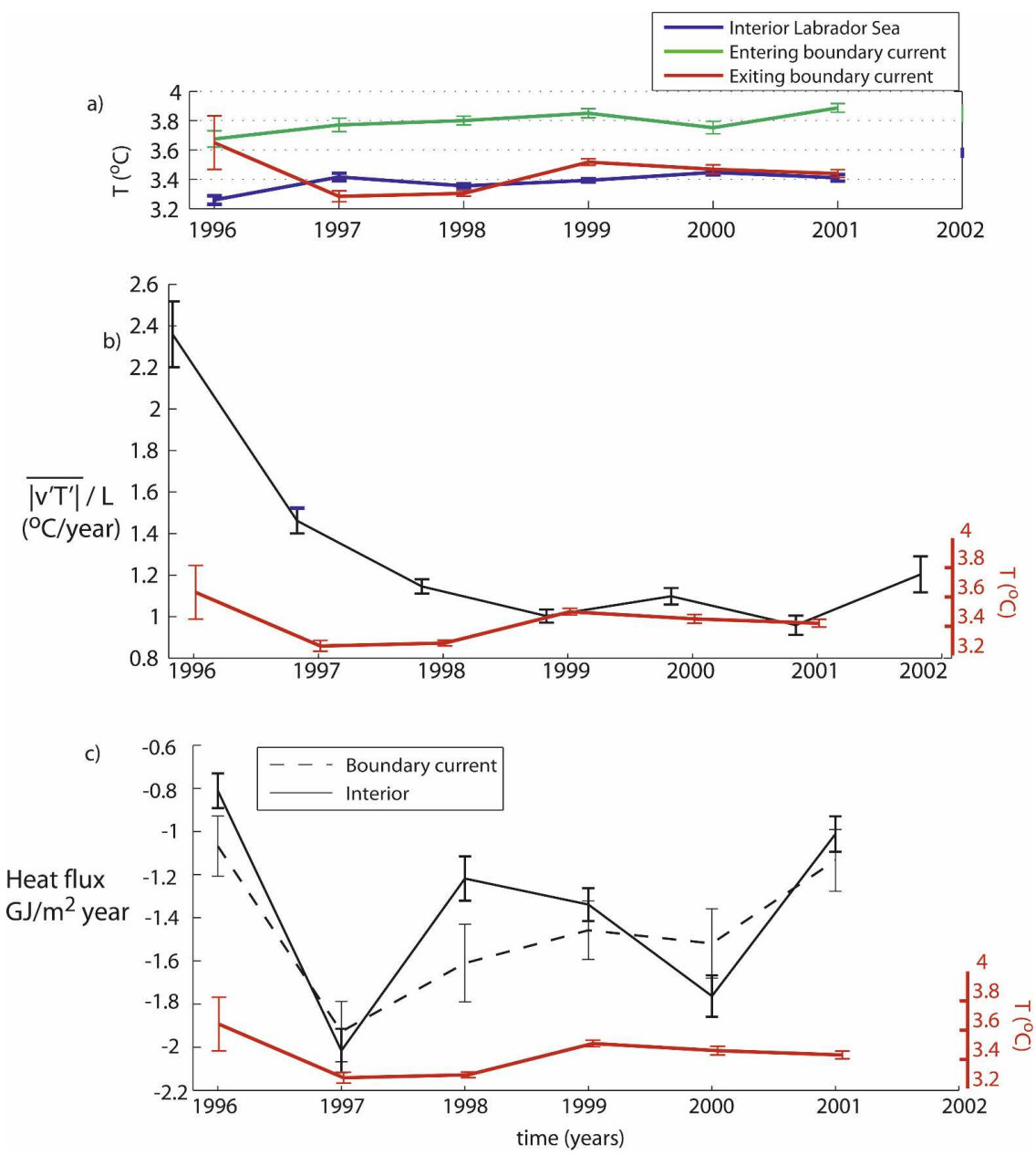

FIG. 11. Interannual variability of LSW temperature and heat fluxes. All values are calculated from May of the previous year through April of the indicated year, as in Straneo (2006a). Error bars are \pm 1 standard error. (a) Annual mean temperature on $\sigma_{\theta}=27.74$ in the interior Labrador Sea (blue), entering boundary current (green), and outgoing DWBC (red). The categories are determined by the profile geographical locations, as shown in Fig. 3. (b) Annual average $\left|v^{\prime} T^{\prime}\right|$, over the entire Labrador Sea domain, divided by a length scale of $100 \mathrm{~km}$. The temperature of the exiting DWBC appears in red (right axis). (c) Integrated annual ECMWF heat fluxes over the boundary current (dashed) and interior Labrador Sea (solid). ECMWF provides surface flux data on a $2.5^{\circ}$ spatial grid, providing seven boxes over the interior Labrador Sea and nine over the boundary current, as defined by the bathymetric criteria.

to play a leading role in the entry of LSW into the DWBC during the float years: the heat loss recorded by a single float of $6 \mathrm{GJ} \mathrm{m}^{-2}$ in only eight months during its swift circuit of the Labrador Sea in 2002 is greater than the inferred advective or eddy fluxes. However, it is difficult to evaluate how the profiles along the trajectory of a single float translate to the average cooling in the DWBC and what portion of this cooling is due to direct heat loss to the atmosphere as opposed to lateral fluxes from the interior. Therefore, we use heat flux reanalysis data to evaluate the impact of atmospheric forcing directly on the DWBC (Fig. 11c). Although the cooling of the water column is dependent both on its initial conditions and heat loss along its Lagrangian trajectory, the heat fluxes alone still shed some light on where LSW is likely to be formed. In the western extension of the DWBC, the water column has been conditioned during its transit of the Labrador Sea to closely resemble the interior such that profiles in the DWBC and interior can be nearly identical. Here, where the flow has a strong barotropic component (Lazier and Wright 1993), it is expected that a given heat flux would result in essentially indistinguishable mixed layers in the exiting DWBC and the interior. European Centre 
for Medium-Range Weather Forecasts (ECMWF) reanalysis was chosen over National Centers for Environmental Prediction (NCEP) reanalysis (Kalnay et al. 1996) because of its high fidelity to observations in the Labrador Sea region during the Labrador Deep Sea Convection Experiment (Renfrew et al. 2002). Nonetheless, NCEP heat fluxes, which are available on a higher-resolution grid ( $1.5^{\circ}$ square), show similar temporal variability when analyzed in the same way.

The annually integrated heat fluxes over both the boundary current and interior Labrador Sea vary by a factor of 6 over the float years, with the strongest heat loss in 1997. The interior has slightly stronger heat losses than the boundary current in only two of the recorded years; in other years the losses are indistinguishable. Cooling is known to be spatially patchy over the Labrador Sea (Pickart et al. 2002), a result substantiated by the large standard deviations of the ECMWF heat fluxes, which amount to roughly half of the total estimated heat flux in both the boundary current and interior (not shown). Such spatial variability of the atmospheric forcing is expected to give rise to significant temporal variability in the outbound LSW. This appears to be very much the case, as the temperature of the 27.74 isopycnal in the boundary current cools considerably in 1997 (Fig. 11a). As illustrated by the float profiles and trajectories, cooling directly in the boundary current creates a fast track for LSW export from the Labrador Sea.

\section{Summary and conclusions}

This analysis of (P)ALACE float trajectories and profiles establishes the heat loss from the DWBC brought about by the direct flux from the boundary current to the atmosphere and advective-diffusive exchange between the boundary current and the interior Labrador Sea. Although each mechanism had been implicated in the transfer of LSW into the DWBC in previous studies, this analysis is unique in that it compares the contribution of three mechanisms directly from one dataset, looks at the heat losses in the boundary current from a quasi-Lagrangian perspective, and quantifies the cross-stream eddy heat flux from direct observations. It is concluded that each mechanism examined here has the potential to play a role in the removal of heat from the boundary current. The flux of LSW from the interior Labrador Sea in a horizontally divergent mean flow at depth is the most uncertain of the estimates, as the variability of the mean flow is large over the limited number of years during which the floats were operational. Moreover, whether a compensating convergent surface flow exists cannot be resolved with the available data. Both the eddy exchange mechanism and the loss of heat directly from the boundary current are shown to be possible sources of interannual variability for the exported LSW product.

Acknowledgments. It is a pleasure to acknowledge insightful conversations with Fiamma Straneo, Amy Bower, and Fritz Schott. The constructive comments of two anonymous reviewers are also gratefully acknowledged. The heat flux data were provided by the European Centre for Medium-Range Weather Forecasts (ECMWF) from their data server (http://www.ecmwf. int/index.html). We are also grateful to the NSF for their support of this research.

\section{REFERENCES}

Bower, A. S., and H. D. Hunt, 2000: Lagrangian observations of the deep western boundary current in the North Atlantic Ocean. Part II: The Gulf Stream-deep western boundary current crossover. J. Phys. Oceanogr., 30, 784-804.

Curry, R. G., M. S. McCartney, and T. M. Joyce, 1998: Oceanic transport of subpolar climate signals to mid-depth subtropical waters. Nature, 391, 575-577.

Davis, R. E., J. T. Sherman, and J. Dufour, 2001: Profiling ALACEs and other advances in autonomous subsurface floats. J. Atmos. Oceanic Technol., 18, 982-993.

Dengler, M., J. Fischer, F. A. Schott, and R. Zantopp, 2006: Deep Labrador Current and its variability in 1996-2005. Geophys. Res. Lett., 33, L21S06, doi:10.1029/2006GL026702.

Dickson, R., J. Lazier, J. Meincke, P. Rhines, and J. Swift, 1996: Long-term coordinated changes in the convective activity of the North Atlantic. Prog. Oceanogr., 38, 241-295.

Fischer, J., and F. A. Schott, 2002: Labrador Sea Water tracked by profiling floats-From the boundary current into the open North Atlantic. J. Phys. Oceanogr., 32, 573-584.

,-- , and M. Dengler, 2004: Boundary circulation at the exit of the Labrador Sea. J. Phys. Oceanogr., 34, 1548-1570.

Fratantoni, D. M., 2001: North Atlantic surface circulation during the 1990's observed with satellite-tracked drifters. J. Geophys. Res., 106, 22 067-22 093.

Kalnay, E., and Coauthors, 1996: The NCEP/NCAR 40-Year Reanalysis Project. Bull. Amer. Meteor. Soc., 77, 437-471.

Katsman, C. A., M. A. Spall, and R. S. Pickart, 2004: Boundary current eddies and their role in the restratification of the Labrador Sea. J. Phys. Oceanogr., 34, 1967-1983.

Kieke, D., M. Rhein, L. Stramma, W. M. Smethie, D. A. LeBel, and W. Zenk, 2006: Changes in the CFC inventories and formation rates of upper Labrador Sea Water, 1997-2001. J. Phys. Oceanogr., 36, 64-86.

Lab Sea Group, The, 1998: The Labrador Sea Deep Convection Experiment. Bull. Amer. Meteor. Soc., 79, 2033-2058.

Lavender, K. L., R. E. Davis, and W. B. Owens, 2000: Mid-depth recirculation observed in the interior Labrador and Irminger seas by direct velocity measurements. Nature, 407, 66-69.

,$- \ldots$, and 2002: Observations of open-ocean deep convection in the Labrador Sea from subsurface floats. J. Phys. Oceanogr., 32, 511-526.

W. B. Owens, and R. E. Davis, 2005: The mid-depth circu- 
lation of the subpolar North Atlantic Ocean as measured by subsurface floats. Deep-Sea Res. I, 52, 767-785.

Lazier, J., and D. G. Wright, 1993: Annual velocity variations in the Labrador Current. J. Phys. Oceanogr., 23, 659-678.

- , R. Hendry, A. Clarke, I. Yashayaev, and P. Rhines, 2002: Convection and restratification in the Labrador Sea, 19902000. Deep-Sea Res. I, 49, 1819-1835.

Pazan, S. E., and P. Niiler, 2004: New global drifter data set available. EOS, Trans. Amer. Geophys. Union, 85, 17.

Pickart, R. S., and W. M. Smethie, 1998: Temporal evolution of the deep western boundary current where it enters the subtropical domain: Evidence from tracer data. Deep-Sea Res. I, 45, 1053-1083.

— , and M. A. Spall, 2007: Impact of the Labrador Sea convection on the North Atlantic meridional overturning circulation. J. Phys. Oceanogr., 37, 2207-2227.

— W. M. J. Smethie, J. R. N. Lazier, E. P. Jones, and W. J. Jenkins, 1996: Eddies of newly formed upper Labrador Sea Water. J. Geophys. Res., 101, 20 711-20 726.

_ M. A. Spall, and J. R. N. Lazier, 1997: Mid-depth ventilation in the western boundary current system of the sub-polar gyre. Deep-Sea Res. I, 44, 1025-1054.

— D. J. Torres, and R. A. Clarke, 2002: Hydrography of the Labrador Sea during active convection. J. Phys. Oceanogr., 32, 428-457.

—, M. A. Spall, M. H. Ribergaard, G. W. K. Moore, and R. F. Milliff, 2003a: Deep convection in the Irminger Sea forced by the Greenland tip jet. Nature, 424, 152-156.

, F. Straneo, and G. W. K. Moore, 2003b: Is Labrador Sea
Water formed in the Irminger Basin? Deep-Sea Res. I, 50, 23-52.

Renfrew, I. A., G. W. K. Moore, P. S. Guest, and K. Bumke, 2002: A comparison of surface layer and surface turbulent flux observations over the Labrador Sea with ECMWF analyses and NCEP reanalyses. J. Phys. Oceanogr., 32, 383-400.

Rhein, M., and Coauthors, 2002: Labrador Sea Water: Pathways, CFC inventory, and formation rates. J. Phys. Oceanogr., 32, 648-665.

Schott, F. A., J. Fischer, M. Dengler, and R. Zantopp, 2006: Variability of the Deep Western Boundary Current east of the Grand Banks. Geophys. Res. Lett., 33, L21S07, doi:10.1029/ 2006 GL026563.

Stramma, L., D. Kieke, M. Rhein, F. Schott, I. Yashayaev, and K. P. Koltermann, 2004: Deep water changes at the western boundary of the subpolar North Atlantic during 1996 to 2001. Deep-Sea Res. I, 51, 1033-1056.

Straneo, F., 2006a: Heat and freshwater transport through the Central Labrador Sea. J. Phys. Oceanogr., 36, 606-628.

- 2006b: On the connection between dense water formation, overturning, and poleward heat transport in a convective basin. J. Phys. Oceanogr., 36, 1822-1840.

- R. S. Pickart, and K. L. Lavender, 2003: Spreading of Labrador Sea Water: An advective-diffusive study based on Lagrangian data. Deep-Sea Res. I, 50, 701-719.

Talley, L. D., and M. S. McCartney, 1982: Distribution and circulation of Labrador Sea Water. J. Phys. Oceanogr., 12, 1189 1205 . 
Copyright of Journal of Physical Oceanography is the property of American Meteorological Society and its content may not be copied or emailed to multiple sites or posted to a listserv without the copyright holder's express written permission. However, users may print, download, or email articles for individual use. 